\title{
Expectations and Ideal VRUI from User's Perspective, Case Studies: VR Interface in ITB Electric Car's (Molina) Virtual Exhibition
}

\author{
Zita Nadia*, Yannes Martinus Pasaribu, Imam Damar Djati \\ Bandung Institute of Technology, Faculty of Visual Art and Design, Jalan Ganesha 10, Bandung, West Java, \\ Indonesia. \\ * Corresponding author. Tel.: +62 81319294 273; email: zitanadia25@gmail.com \\ Manuscript submitted June 20, 2017; accepted August 2, 2017. \\ doi: 10.17706/jcp.13.6.721-732
}

\begin{abstract}
Virtual Reality (VR) is a phenomenon in technology, it has been a fast-grown technology for the past 2 years, and it is common to find them in automotives industry. "Expectations and Ideal VRUI from user's perspective, Case Studies: VR Interface in Electric Car's Virtual Exhibition" is chosen as the topic for this research. The selected case study in this research is virtual reality user interface (VRUI) from ITB electric car's virtual exhibition, because interface has an important role to help user having a great interaction in virtual world, just like in virtual exhibition. User Experience's approach system is chosen in order to help to understand the ideal experience of VRUI from user's perspective and needs, thus the designers and developers are able to develop the VRUI based on those factors. The expected results we could get from this research are; to design a VRUI application, we can use the same methods as creating the 2-dimension UI and using user's expectation as a tool to fulfill the user needs for VRUI.
\end{abstract}

Key words: Expectations, user experience, virtual exhibition, VRUI.

\section{Introduction}

Virtual Reality (VR) is a technology that can transport human consciousness into another reality, the user will feel the presence of virtual world even though not physically present inside the virtual world [1]. The transportation phase used VR gadgets like Oculus Rifts and Samsung Gear VR. VR also means as an individual experience related to one kind of technology, where the world given by the technology could present the nature that connected to other fields like social relation and meaning [2].

VR technology is not a newly developed technology. It has already found in 1930, where the flying simulator invented by Edward Link has become the pioneer of this technology [2]. At 1950's, Morton Heilig tried to make his HMD (Head Mounted Display) Telesphere [3] invention to be commercially available to the public, but it failed due to the market was not ready yet. However, the development of VR technology has never stopped there. In 2016 it was called as the development of VR year, as we can see from so many new VR gadgets, and some of social media platforms now are supporting VR contents, such as Youtube and Facebook.

VR besides use for photo and video, we can easily find it in simulations form. The usage of VR as simulation can be found in many different fields such as war simulator, flying simulator, operation simulator in medicine world and virtual exhibition simulation. The virtual exhibition simulation is now developing in 2 big industries, like museums and automotive industry. In automotive industry, virtual 
exhibition can be seen in many forms like virtual tour, virtual showroom and driving simulation.

The usage of VR as exhibition has many benefits, such as it only takes a little space (if use mobile VR), and cost effective (when in car show, where the car could not physically present because of some limitations), and also has information efficiency and have strong performance effect [4]. Inside the virtual exhibition in apps form, virtual reality user interface (VRUI) have important task in human computer interaction, especially to help user understanding and operating the VR system. To create a VRUI that fulfill user needs, we use User Experience (UX) approach to indentify the user's perspective as we can see in Fig. 1.

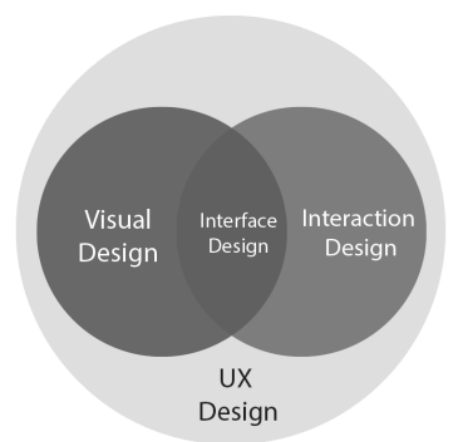

Fig. 1. Dan saffer UX diagrams [5].

User Experience is the general subject from interface design, and it is a great tool to help creating a great user interface design, because interface design is still a part of User Experience design. Interface is the 'language' between human and the computers, and it gives the user the ability to do things [6] with the command given to the computer, such as VR system. In order to create good interface design we need guidelines, where usually the interface design guidelines based from human psychology, like one expert in this fields is Donald Norman, who has a background in cognitive psychology and invented the term of user experience [7].

User experience is an entire process when a human interacts with a product, system or device in this case is VR apps, the whole process before and after interaction with the product [8]. The interaction has a broad meaning, it is include the phase before any physical interaction with the product occurs, like thinking about the products and expectation. Expectation is playing important role where the fulfillment (confirmation) of user expectation will lead to repurchase of the products or the continuance usage of the service or products, and it plays important role to help the technology business lasts [9], especially for new technology like VR, and user experience can help designer or developer to meet the user expectation, because its main focus is user's perspective. Expectation in user interface is have an effect to user perception, because what they expect to see is what user has already seen on the other display before [7], so it is important to know the expectation when developing VRUI, for the designer who just join the VR world.

Designer and Developer need to know how to design VRUI, because when there is changing era from static to dynamic interface, designer found some difficulties to adjust with the new UI [10] but apparently research about application of VRUI is only a few [11], one of the research about application and designing VRUI we can find in Alger research about visual methods of designing virtual reality, but it focused on how creating home screen for VR apps [12]. And it has different contents with this research that focused on creating VRUI for virtual exhibition application from the user perspective. User expectation about VRUI will be covering the aspect of the vrui itself, like interaction, simulation, visualization, real space and immersion [13], but in the context of electric public transportation like molina. In this research we can see the process before user (participants) interacts with the VR apps, and after interact through FGD session,and in the end 
we can get some design suggestion than can be used by the designer and developers aim for this research can we see from the research question:

\subsection{Research Questions}

A. Is there any relations between user expectations and the ideal VRUI?

B. How did the user define the ideal VRUI according to their perspectives?

Several theories used in this research, like 3I of VR by Burdea and Coiffet [14] and Cybersickness that could interrupt the process of experience with VR technology and give influence to research outcomes. Application of VR technology in the virtual exhibition certainly will not be separated from, the main aspect of virtual reality, where the good virtual exhibition should be able to have the third strength aspects of VR. The strength of VR can we see from triangle VR that belong Burdea and Coiffet [14], or also known as the 3I of VR of which are:

1. Immersion: associated with the feeling being presence inside the virtual environment (VE) [1], immersion also have strong ties with environment that were generated by the computer system that become a main characteristic of VR system.

2. Interaction: connection and communication between user and VR system, also associated with the VR system capability to detect action and user gesture as input and responded in VE according input given by the user [1]

3. Imagination : the ability of mind to percept inexistent things, where the user will believe the environment generated by the VR system really exist [14]

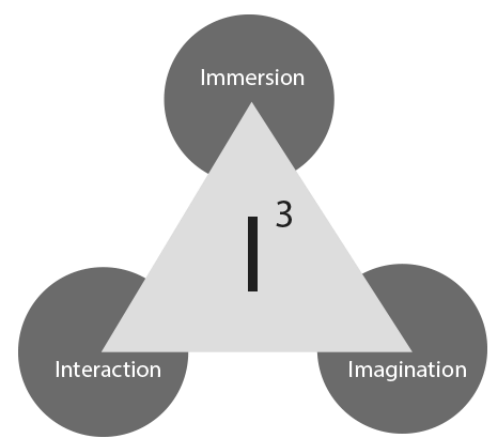

Fig. 2. Burdea and coiffet 3I of VR [14].

The utilization of these three aspects which have been mentioned above, can produce an optimal experience for user while using VR system, 3I can be used by developers and designers to create pleasing and great VR experience for user. Interaction inside the VR system plays important role, besides become of one aspects of 3I, it could be features that user like most, but it has one risk that called cybersickness (CS), where it is a form of motion sickness but this caused by the VE [15].

Stanney also stated that CS could give a serious threat to usability of VR system, there are a lot of severity degree of CS, started from the light one like dizzy, headache and nausea (Kalawsky in Stanney)[145, and in some rare case could make user vomit but it is almost unlikely to happen [14]. Cybersickness matter plays important role because it will make user avoid future interaction with VR system to avoid the feeling of sickness.

Risk mentioned before will influence user interaction when facing VR system, another aspect besides CS risk that can influence is user expectation when interact with VR. As new technology, expectation will play important role, because if user expectation does not meet by the developer it will have an impact whether they will continue use the products or not, but in different perspective user expectation that has not been 
fulfill will be a chance to developing VR as the user wants and needs, in this research expectations can be use as a tooll to see the ideal VRUI according to user.

\section{Methods}

In this research, researcher used many different tools like expectation form, questionnaire about the experience given, and FGD (Focus Group Discussion) to get how user determined ideal VRUI according to their perspective. This research was conducted in 5th and 9th January 2017. There were 10 participants in this research which divided in 2 groups, each group consisted of 5 participants. The characteristics of participants are, master students from design major who already had experience using automotive virtual exhibition. The experiments has 3 phases, the first phase is the expectation phase, where the participants fill the expectation form before use the apps provided by us. The second phase is the testing phase, the participants use the apps for 5 minutes and after that fill the questionnaire about the experience they had, and the last phase is FGD for 1 hour, the aim of this phase is to find the ideal VRUI according to the user perspective.

\section{First Phase: Expectations Phase}

Expectations phase is to see how participants expect when they encounter virtual exhibitions apps like Molina's VR virtual exhibitions apps, because the ideal VRUI could be seen from user mental model when see something. In this session we gathered so many expectations points, so we divided them into different categories, at first there were 12 categories, but we narrowed it down to 7 categories of participants exhibitions as seen at Table 1.

Table 1. User Expectation Category

\begin{tabular}{l|l}
\hline \multicolumn{1}{c|}{ Categories } & \multicolumn{1}{c}{ Expectations } \\
\hline Scenarios and Exhibition Information & $\begin{array}{l}\text { Scenario about we get in and off and payment } \\
\text { system inside the Molina } \\
\text { Information about Molina passenger capacity and } \\
\text { the difference between Molina and the existing } \\
\text { public transportation } \\
\text { Detailed narration about Molina } \\
\text { Information about how we operate the electric } \\
\text { vehicle and what parameters we should pay } \\
\text { attention } \\
\text { Features, Design and Graphic Resolution }\end{array}$ \\
\hline Pafety Instruction for the future passenger (in this \\
case are the participants)
\end{tabular}




\begin{tabular}{|c|c|}
\hline Car's Exterior and Interior & $\begin{array}{l}\text { Molina's exterior displayed from different POV } \\
\text { and perspectives. } \\
\text { Car's interior in different condition like the one in } \\
\text { full passenger condition and empty from } \\
\text { passenger. } \\
\text { Car's exterior and interior can be customized. } \\
\text { Molina facility like trash can and safety features. }\end{array}$ \\
\hline Test Drive & $\begin{array}{l}\text { Test Drive available but when in driving mode, } \\
\text { should involved less winding road part to avoid } \\
\text { cybersickness. }\end{array}$ \\
\hline User Interface (UI) & $\begin{array}{l}\text { UI easily used and have complete ui elements. } \\
\text { Blinking arrow could help to direct user attention } \\
\text { "Enter" button to help user enter certain scene } \\
\text { inside the virtual world. } \\
\text { Animation transitions effect, when user changing } \\
\text { scene or choosing icon, so the transitions feel } \\
\text { smoother. } \\
\text { Icon has descriptions that place below of it, the } \\
\text { help user understands its function, and } \\
\text { availability icon that describe vehicles part } \\
\text { function. } \\
\text { Zooming features }\end{array}$ \\
\hline Scenery & $\begin{array}{l}\text { Scenery Molina when at the bus stop, wait at the } \\
\text { bus stop and the process to get in to Molina when } \\
\text { arrived. } \\
\text { Molina on different setting like day and night } \\
\text { mode. } \\
\text { Molina on different road mode, like at empty road, } \\
\text { rush hour or stuck in traffic jam. } \\
\text { Scenery inside the Molina, with its driver and } \\
\text { another passenger. }\end{array}$ \\
\hline
\end{tabular}

As we can see the participants expectations are influenced by their experience in the real world, where it is can be seen at scenery category where, they wish is the Molina that they can see in the virtual world has a sense of closeness with the public transportation car they see in the real world, even from the visual aspect and from experience aspect.

Respondents are also wish the apps has test drive features, but with a scene that include a small amounts of winding road to avoid dizziness, this thing is the same as Barfield and Werghorst said in Kenney [15] that participants will seek any ways to avoid cybersickness, because of some the participants used in this research has an experience with Relay Cars 5 (automotive exhibition apps) and complained about CS when interacted with it, and it influenced the outcome.

User Interface (UI) is one of category with the most expectations inside, at first participants expecting a good UI to make them easier using and navigating inside the Molina apps, zooming feature is also expected by them. Another UI element that expected was the existence of icon that functioning, and easy to understand, to help participants understand the icon, designers could add some descriptions under the icon. It should have some animations effect so it can gives smoother transitions between scene or features to add some sensation inside the virtual world. 


\section{Second Phase: Apps Testing and Questionnaire Phase}

The second phase of the experiment is the apps testing and questionnaire phase, after the participants have finished using the apps given within the time limit, they filled the questionnaire. Apps given in this phase is Molina virtual exhibition apps, and the gadget used is Samsung Gear VR 2, each participant has 5 minutes to experience the apps, because the apps given still a prototype with simple features. The questionnaire consist several item questioning about their experience when interact with Molina virtual exhibition apps, because there only 10 participants in this research, the response read as tendency data, which the closer response to strongly agree it will count as positive data and so otherwise.

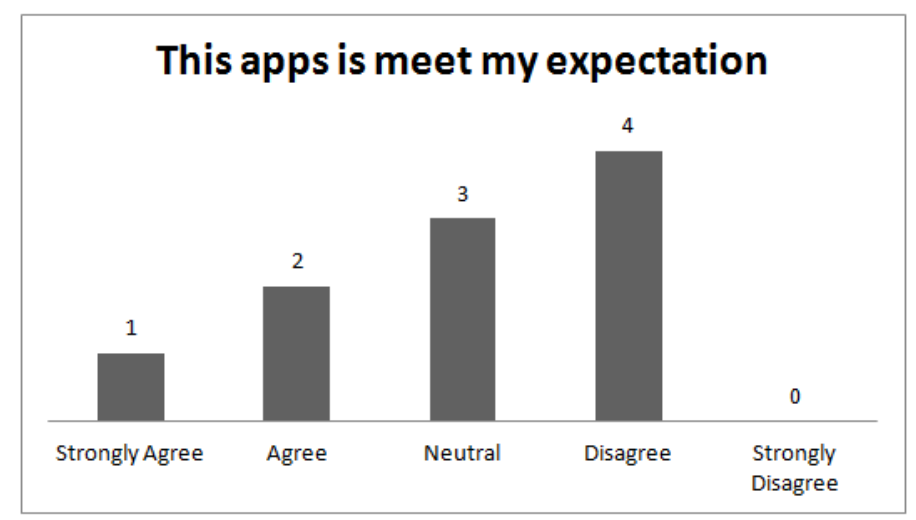

Fig. 3. Participants expectations charts.

User expectation as seen at Fig. 3. showed it has not fulfilled by Molina virtual exhibition apps, as we can see most participants answered "not agree". This could happen because of apps that given as research object is too simple with limited interactivity because of gadget limitations, and we can see from expectations results, participants demanded more complex features like interaction and POV.

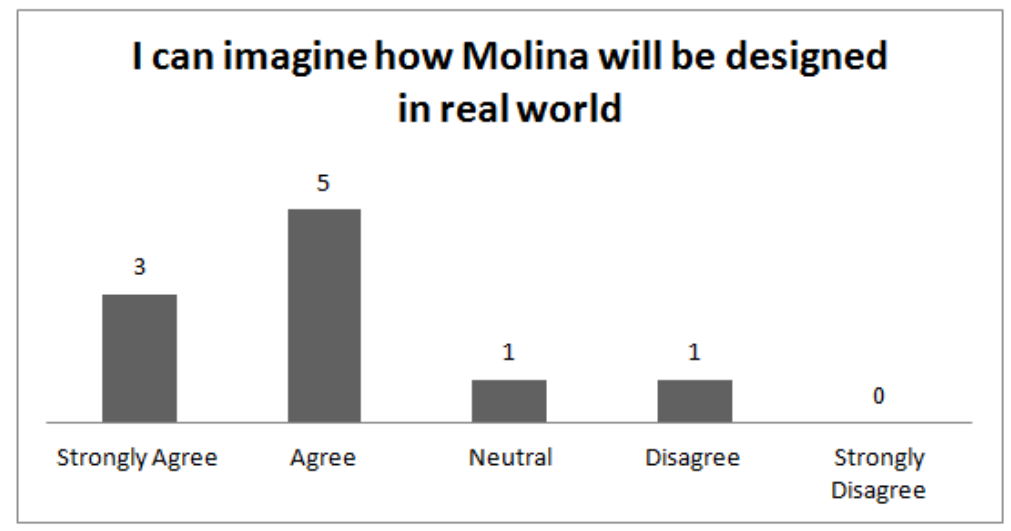

Fig. 4. Molina apps imagination chart.

Virtual Reality turns out to be shown to have the power to give an overview to the participants to imagine how Molina physically will be designed Fig. 4, this is the same with the statement of the Burdea and Coiffet [14], where VR has the power of imagination to make the user able to imagine what is shown by the VR system. This also show the potential of VR system have as presentation tools in automotive world, it could help the automotive designers to create an image for user even when the prototype is not physically ready and used virtual model inside the VR system instead. 


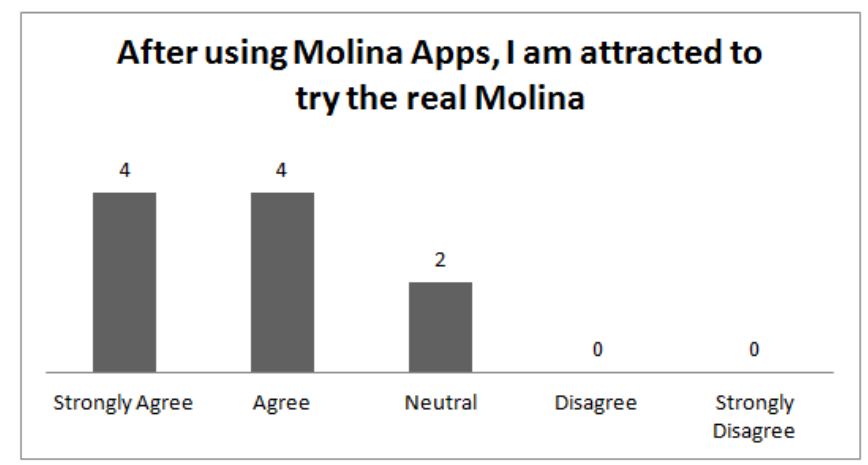

Fig. 5. Molina apps persuasion charts.

Another power of VR system is capable to persuade respondents to try Molina directly after see Molina inside the virtual world (Fig. 5.), it can be a chance for VR to be used as the media to attract users attention to try the physical car before they see it in the real world, because it can give an information in attractive ways that could not be given by the other media, but for the best experience in automotive industry, we recommended to use the actual car, not virtual car, because the main point of VR system is giving information that can be experience by the user, not the actual experience itself.

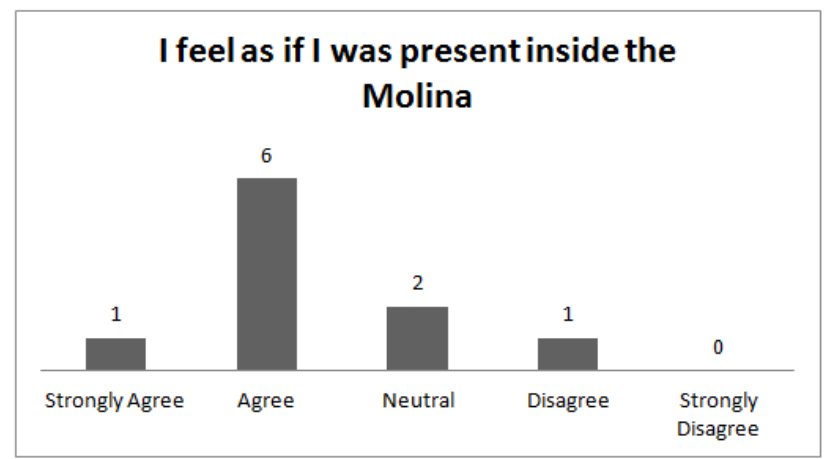

Fig. 6. Immersion chart of molina apps.

Virtual Reality has strong aspect that called 3 Iof VR [3], 3I means Interaction, Immersion and Imagination. Aspects that very dominants in this case is immersion, if we look at (Fig. 6.), where the most participants frequently respond "agree" about the feeling of being presence inside the real car when trying virtual Molina applications interior features, but there is still a negative response due to, participants felt the proportion of interior features still confuse them to find out the real size of the interior of Molina.

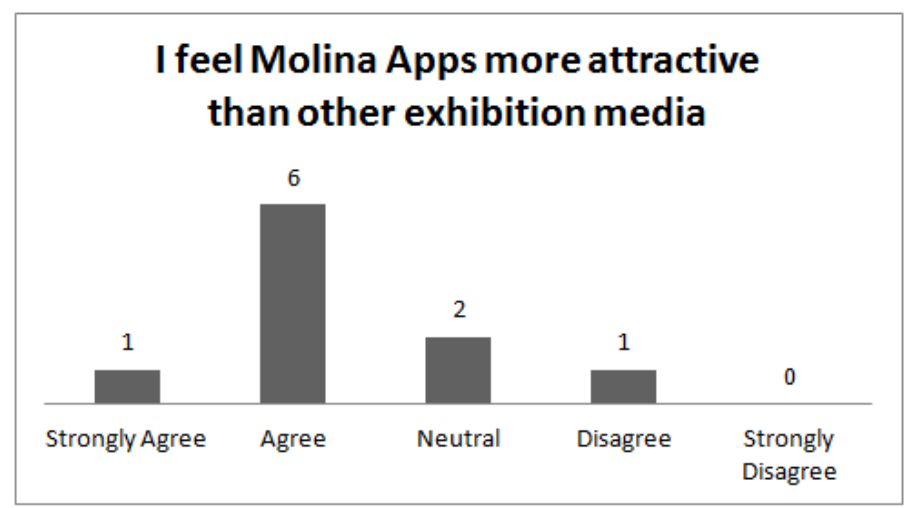

Fig. 7. Molina apps attractive level chart. 
Fig. 7 shows that Virtual Reality as a medium can also be considered as a medium is more attractive when compared to other media, such as LCD, brochures, banners and more, this is because VR has the interactions that much higher when compared to other media, and as mentioned before VR can presence information that feel and experience by the user, like in this case studies, the information present inside the interior features is interior of Molina's, but because we using VR when we present it, the user could immerse inside the information given.

The whole experience of using virtual exhibition Molina's apps can be measured through emocard from Desmet [16]. Emocard is chosen because it could measure the participants' mood through a visual form, that maybe can not be expressed through the word chosen by the researcher team. The participants choose one of the emocard present to rate their whole experience, the result can we see at (Fig. 8.)

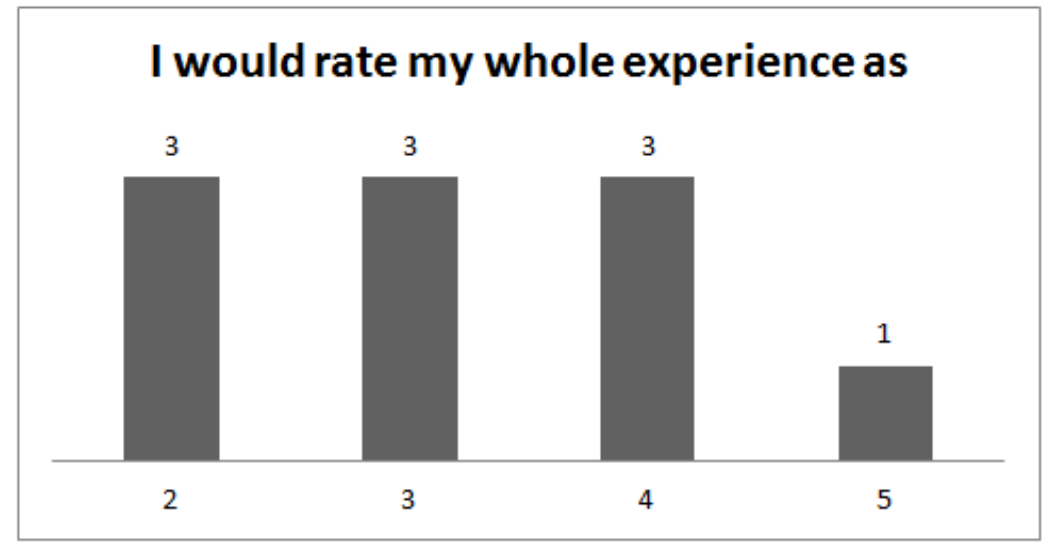

Fig. 8. Whole experience rate chart.

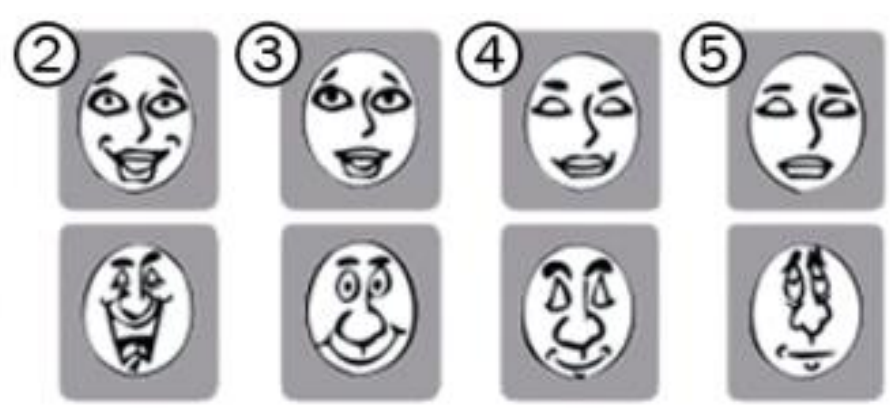

Fig. 9. Emocard, 2: excited pleasant, 3: average pleasant, 4: calm pleasant, 5: calm neutral.

The chart shows the respondents have tendency to refer to positive emotions, because most of the response from the participants refer to number 2 to 5 , so it can be inferred the respondents enjoyed the experience when interacting with a virtual exhibition application Molina. Positive reactions can caused from the enthusiasm of the participants facing VR as one of the new technologies that popular at the moment.

\section{Third Phase: Focus Group Discussion (FGD) Phase}

Focus Group Discussion (FGD) phase takes approximately 1 hour with the aim to find the ideal virtual exhibition VRUI for Molina. There are a lot of input about the virtual exhibition, to narrow it down the input is divided into into several categories, the number of categories found researchers are 10 categories that we can see in the following table: 
Table 2. FGD Categories and Ideal VRUI Table

\begin{tabular}{l|l}
\hline Colour & \multicolumn{1}{c}{ Findings } \\
\hline Point Of View (POV) & $\begin{array}{l}\text { The colour contrast in some part of the apps was } \\
\text { refer as acceptable by the participants, but in } \\
\text { some parts the contrast was too high and } \\
\text { distracting user vision. }\end{array}$ \\
\hline Test Drive & $\begin{array}{l}\text { Participants hope apps could provide them with } \\
\text { different POV, especially for the interior feature, } \\
\text { they said it could be delivered in apps menu } \\
\text { option or real time interaction. }\end{array}$ \\
\hline Shadow & $\begin{array}{l}\text { The unavailability of test drive feature makes } \\
\text { participants disappointed, because the test drive } \\
\text { feature is the most wanted feature for } \\
\text { participants, because it can deliver information } \\
\text { they want to see }\end{array}$ \\
\hline
\end{tabular}

Cursor

The cursor function inside the apps, felt by the participants not functioning well, because it can suddenly disappeared and changing position, but it plays important role to help user understand which direction they look at

Interior

Availability of interior features that can be customized, like the colour and material.

Participants agree, that interior will always be the content that public seek when encounter Molina apps.

The distortion felt too much by participants, and it caused "floating" feel, because the floor seems too far.

Scenery

Scenery that show Molina in different condition, like at day an night time, and scenery surrounding Molina, like tracks, passenger and bus stop.

Information

Information felt by the participants as not relevant with the user needs.

Information about route, tickets price and sitting layout, passenger capacity felt important to show inside the apps, and whole scenarios about how they should do inside Molina.

Comparison between Molina and existent technology used in public transportation, so user can see the benefits and novelty used in Molina.

Campaign about electric public transportation 


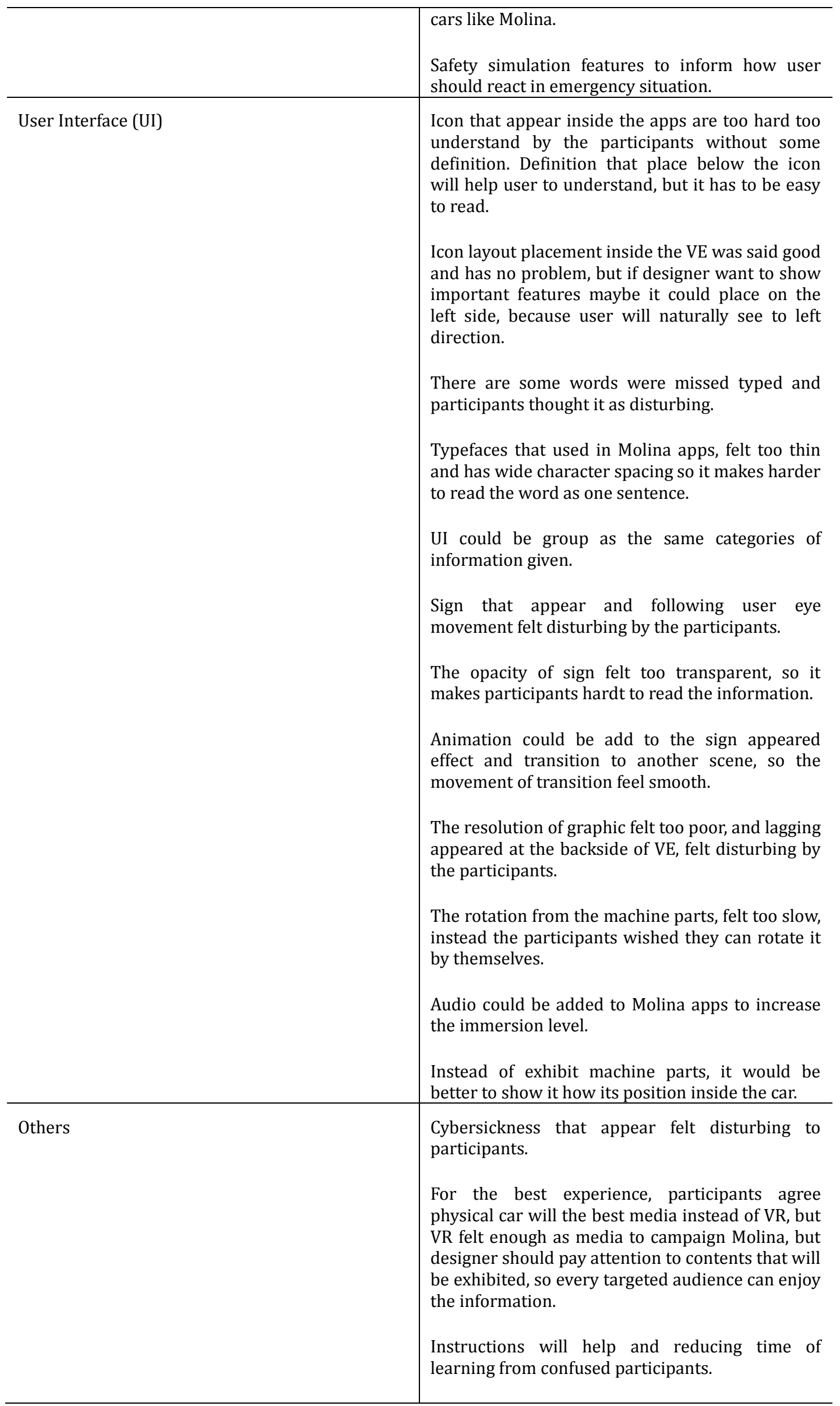


Interesting things that can be found from the above tables is the similarity with expectation phase, a lot of things were repetition they mention before, only few new things are discovered, so that it can be concluded that the ideal given the user derived from the expectations of the user.

UI category is one of category that contain the most input from participants during FGD session, the input is often mention about the selection of typefaces that not suitable for applications inside the virtual world, because the typefaces are too thin and hard to read. UI icon also appeared difficult for the participants to understand, so they need some description to help what kind of the function represented by the icon, participants also mentioned for designer who wants designed in 3D like VRUI could use the approach of designing 2D UI like the one we usually see on smart phones. This one is match with Jeff Johnson [7] statement where user will using interface easier when recognizing than recalling, which is designing VRUI elements using similarity aspect with 2D will help user recognize instead learning new things that can be extra effort for user cognition system.

Participants also said that the virtual layout within the virtual world inside the apps is well done placed, it has comfortable viewing distance, but a little enhancement like grouping the display object into the same categories could help the design and user to understand the information.

Other elements of the UI that become the main topic of discussion is about information, information that exists if seen based on the results of questionnaires already able to deliver new knowledge, but in terms of the suitability of the information is still considered less appropriate, because according to the results of the FGD general public will be more happy to see about details when interacting with Molina when associated with the content of public service vehicles, such as its current state full and empty passengers, routes, and ticket information not the one they see inside the Molina virtual exhibition apps that show cars engine.

Comparisons of technology used in Molina with the public transportation that exist today in Bandung can also help to increase the knowledge and interest of the user to use Molina, because users will be easier to understand the novelty and advantage of using Molina as their main public transportation.

\section{Conclusion}

In conclusion, ideal VRUI according to the user perspective contains several different aspects, from visual aspects users decided that icon is still the best solution to help them navigate and understand the function of a featurs, with the same design approach when designing 2D UI icon. Designer must also pay attention to the readability of typeface and information that placed inside the VE. Features also can be seen as inseparable parts of VRUI, where in the case of Molina virtual exhibition, features and information that provide similarity and closeness to the real world experience is still the best features according to the user. And as we can see the ideal VRUI derived from user expectations and they mentioned it again inside the FGD phase when they see their expectation has not been able to meet by the developer of Molina Virtual Exhibition Apps.

\section{Acknowledgment}

"F. A. Author thanks to ITB for the opportunities to research about this topics, and to all participants who willing give some of their time to be involved within the experiments, and all the party that support this research."

\section{References}

[1] Rebelo, F., Noriega, P., Duarte, E., \& Soares, M. (2012). Using virtual reality to assess user experience. Human Factors, 1-19.

[2] Hillis, K. (1999). Digital Sensations: Space, Identity, and Embodiment in Virtual Reality. London: 
University of Minnesotta Press.

[3] Sherman, W. R., \& Craig, A. B. (2003). Understanding Virtual Reality: Interface, Application and Design. San Francisco: Morgan Kaufman.

[4] Wang, N., \& Liu, S. (2010). Research on virtual exhibition platform based on user experience. Proceedings of IEEE 11th International Conference on Computer-Aided Industrial Design \& Conceptual Design (pp. 711-714).

[5] Saffer, D. (2007). Designing for Interaction: Creating Smart Applications and Clever Devices. Berkeley: New Riders.

[6] Garrett, J. J. (2011). The Elements of User Experience: User-Centered Design for the Web and Beyond.

[7] Johnson, J. (2010). Designing with the Mind in Mind: Simple Guide to Understanding User Interface. Burlington, USA: Morgan Kauffman.

[8] Hartson, R., \& Pyla, P. S. (2012). The UX Book: Process and Guidelines for Ensuring a Quality User Experience. Elsevier.

[9] Bhattacherjee, A. (2001). Understanding information systems continuance: An expectation-confirmation model. MIS Quarterly, 351-370.

[10] Wood, D. (2009). Interaction Design: Where's the Graphic Designer in the Graphical user Interface?

[11] Nadia, Z. (2017). Interaksi dan ekspektasi pengguna terhadap simulasi pameran otomotif virtual reality. Buku 2 Semnasteknomedia 2017.

[12] Alger, M. (2015). Visual Design Methods for Virtual Reality, Ravensbourne University. Master'S thesis, Ravensbourne University.

[13] Coomans, M., \& Timmermans, H. (1997). Towards a taxonomy of virtual reality user interfaces. Proceedings of International Conference on Information Visualisation (IV97) (pp. 279-284).

[14] Burdea, G. C., \& Coiffet, P. (2003). Virtual Reality Technology. New Jersey: John Wiley \& Sons, Inc.

[15] Stanney, K. (1995). Realizing the full potential of virtual reality: Human factors issues that could stand in the way. Proceedings of Annual International Symposium on Virtual Reality (pp. 28-34). North Carolina: IEE.

[16]Kamp, I. (2012). The influence of car-seat design on its character experience. Applied Ergonomics, 43(2), 329-335.

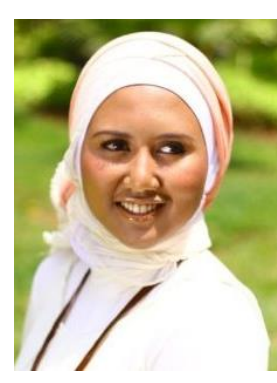

Zita Nadia was born in Palembang, Indonesia in 1990. She obtained the bachelor degree in visual communication design major at Trisakti University in Jakarta in 2012, and currently, she is still engaed in the last year of master degree program at the Faculty of Fine Arts and Design in Bandung Institute of Technology, Bandung, Indonesia. This research is part of her master thesis "User Experience Study in Using Virtual Reality Technology, Case Studies: VR Interface in Electric Car's Virtual Exhibition", as the third part of the data gathering and processing of the research.

Yannes Martinus Pasaribu obtained the bachelor degree in industrial design at Bandung Institute of Technology and completed his master and doctoral degree at Faculty of Fine Arts and Design in Bandung Institute of Technology. Currently, he is a lecture in industrial design at Bandung Institute of Technology.

Imam Damar Djati obtained the bachelor bachelor degree in industrial design at Bandung Institute of Technology in 1996 and completed his master degree at Faculty of Fine Arts and Design in Bandung Institute of Technology at 2000. In 2015, he graduated from Design Science Department, Chiba University in Japan for doctoral degree and gained the doctor of philosophy (Ph.D), currently, he is a lecture in industrial design at Bandung Institute of Technology. 